Etnográfica

Revista do Centro em Rede de Investigação em

Antropologia

vol. $13(1) \mid 2009$

Vol. $13(1)$

\title{
Tão perto de casa, tão longe de nós: etnografia das novas margens no centro da urbe
}

Entrevista com Philippe Bourgois

Luís Fernandes e Philippe Bourgois

\section{(2) OpenEdition}

Journals

Edição electrónica

URL: https://journals.openedition.org/etnografica/1291

DOI: 10.4000/etnografica. 1291

ISSN: 2182-2891

Editora

Centro em Rede de Investigação em Antropologia

Edição impressa

Data de publição: 2 maio 2009

Paginação: 197-211

ISSN: 0873-6561

Refêrencia eletrónica

Luís Fernandes e Philippe Bourgois, «Tão perto de casa, tão longe de nós: etnografia das novas margens no centro da urbe», Etnográfica [Online], vol. 13 (1) | 2009, posto online no dia 22 maio 2012, consultado o 11 fevereiro 2022. URL: http://journals.openedition.org/etnografica/1291 ; DOI: https:// doi.org/10.4000/etnografica.1291

\section{(c) (i) (9)}

Etnográfica is licensed under a Creative Commons Attribution-NonCommercial 4.0 International License. 


\section{Tão perto de casa, tão longe de nós: etnografia das novas margens no centro da urbe}

\section{Entrevista com Philippe Bourgois}

Por Luís Fernandes

Philippe Bourgois é, desde 2007, "Richard Perry University professor" no Departamento de Antropologia e de Medicina Familiar e de Práticas Comunitárias na Universidade da Pensilvânia. Esteve durante largos anos ligado ao Departamento de Antropologia, História e Medicina Social da Universidade da Califórnia, São Francisco. A publicação, em 1995, de In Search of Respect: Selling Crack in El Barrio ${ }^{1}$ projectaria o seu nome muito para além dos Estados Unidos: uma etnografia no coração porto-riquenho do Harlem, em torno dos actores e dos ambientes da venda de crack. Seguir-se-ia um longo trabalho de terreno em acampamentos de dependentes de heroína em São Francisco, orientando o seu trabalho para as formas mais radicais da pobreza e da marginalidade nos EUA. É deste trabalho de terreno que sai o seu último livro, Righteous Dopefiend. ${ }^{2}$ Em Junho de 2007 esteve em Lisboa para participar na 3. ${ }^{a}$ edição do "Ethnografeast”. Foi então que aproveitámos a oportunidade para ouvir um percurso invulgar contado pelo próprio: uma longa conversa no Hotel Zurique, cujo nome só vem ao caso por evocar o país onde passou uma parte da infância.

LUÍS FERNANDES Esta é a segunda vez que estás em Portugal. A primeira foi em 2001, no Porto, onde estiveste na qualidade de especialista do fenómeno droga. Agora estás na qualidade de etnógrafo. De alguma forma estes são os dois campos que definem a tua identidade profissional?

1 Philippe Bourgois, 1995, In Search of Respect: Selling Crack in El Barrio. Nova Iorque e Cambridge, Cambridge University Press.

2 Philippe Bourgois e Jeff Schonberg, 2009, Righteous Dopefiend. Berkeley, University of California Press. 
PHILIPPE BOURGOIS Sim, de certo modo. Mas diria que, mais do que tudo, estudo a pobreza urbana. De maneira etnográfica, claro... e enquanto observador-participante. O meu objectivo é entender o fenómeno daquilo a que eu chamo o "inner-city apartheid", o gueto americano, mas também o fenómeno da marginalização extrema dos pobres e dos novos emigrantes indocumentados nos EUA, especialmente os da América Central. Em São Francisco, onde vivo actualmente, estes são maioritariamente mexicanos e centro-americanos. Os meus contactos foram com ex-guerrilheiros de El Salvador, porque tinha trabalhado aí e feito amizades com combatentes da guerrilha salvadorenha, que por casualidade escolheram a minha cidade, São Francisco, para ser o seu pólo de emigração. Por exemplo, segui as suas experiências como jornaleiros, trabalhadores ao dia sem papéis. Temos este fenómeno nos EUA, de gente que se põe na esquina e se mostra forte para que os contratadores os recrutem por um dia. É como um mercado de músculos, quase de escravos sem direitos. E às vezes há centenas de pessoas à espera na esquina, e dezenas de contratadores que passam, e cerca de 5/6 homens sobem à pick-up e têm talvez um dia, talvez um mês de trabalho, com pagamento mínimo e sem protecção de espécie nenhuma.

LF Ou seja, o campo das drogas já é um pouco longínquo para ti...

PB Não, as drogas e o álcool estão metidos em tudo isso. Porque a pobreza nos EUA se mistura muito na rua com as drogas. E este último estudo, nos últimos 12 anos, com os sem-abrigo, mostrou que ou são totalmente dependentes da heroína, ou fumam crack ou são alcoólicos - ou combinam as três drogas. Os alcoólicos bebem um vinho que é um porto de má qualidade. É tinto como o porto mas muito mais forte...

LF Estudaste os sem-abrigo e a pobreza urbana. Relaciona-la mais com a evolução da América, no teu trabalho de rua em tempos inaugurados pela gestão de Ronald Reagan ou relaciona-la também com movimentos mais mundiais, como a globalização? Pergunto-te isto porque as novas marginalidades urbanas também são um tema em discussão na Europa.

PB Bom, é precisamente isto que vou apresentar na conferência de hoje. Estou a desenvolver uma análise dos efeitos daquilo a que chamo corporate militaristic neoliberalism. Não é um neoliberalismo clássico, no sentido de mercados livres -, porque não são livres, são mercados dominados pelo capital corporativo e são mantidos artificialmente pelo Estado, favorecendo os sectores militares e os monopolistas, como os farmacêuticos. É acompanhado por uma destruição dos serviços sociais e dos mecanismos que procuram desfazer as desigualdades económicas. E, pior, há um gasto imenso com as instituições repressivas. A prisão 
tem mais de dois milhões de pessoas, actualmente, nos EUA. É a taxa mais alta entre os países ricos, industrializados e democráticos - é um Estado penal.

LF Essa última afirmação remete-me para Loïc Wacquant. Subscreves a sua tese sobre o Estado penal?

PB Sim!

LF Às vezes, parece-me um pouco extremada...

PB Quando olhamos para os bairros pobres... As estatísticas globais do país metem medo! Existem mais jovens afro-americanos nas prisões do que nas universidades. Considerando os bairros pobres, verifica-se que a proporção de pobres na prisão é uma loucura. Por exemplo, entre os jovens vendedores de crack sobre os quais escrevi no In Search of Respect, 100\% das raparigas mantêm relações com homens presos ou que saíram da prisão recentemente. Se não estão na prisão estão na rua sob supervisão penal. As pessoas crescem em bairros em que não conhecem pessoas que não estejam na rua ou na prisão...

LF Há uma consciência disso na classe média americana ou é um fenómeno de interstício?

PB Realmente é invisível. É um pouco a polémica de Loïc Wacquant. O bairro é uma frustração. É uma questão a que eu chamaria um não-reconhecimento do fenómeno, é um público secreto nos EUA. Se disseres a um americano que vive num Estado penal, que os EUA têm as taxas mais altas de encarceramento, ele diz que estás louco. Ele considera que vive no país mais livre, mais democrático, que oferece mais possibilidades de autocrescimento. O que chama a atenção nas mudanças dos últimos dez anos das ideologias em torno do neoliberalismo - que é, de facto, celebrado nos EUA - é a noção comum de que a maneira mais eficiente, mais justa e melhor para todos de administrar a sociedade é este sistema de subsídios às empresas, de repressão e cortes nos serviços sociais. Não há nada, constituído como um movimento, que se oponha a isto; existem apenas uns intelectuais por aí e por acolá... mas até nós, os intelectuais, andamos um pouco confusos. Não sabemos nem como explicar o que se passa. Na verdade estou um pouco deprimido...

LF O que dizes relaciona-se com o tema deste encontro, que é o tema das relações entre especialistas, neste caso da etnografia e da antropologia, e a esfera pública. Parece-me que a esfera pública não está muito consciencializada de que se produz dualização social com esta estratégia neoliberal. Ou seja, que papel podemos desempenhar nós, os cientistas sociais, neste campo? 
PB Sim, é certo. De alguma forma, os marginais foram invisibilizados, porque houve uma mudança de estratégias da polícia e das cidades dos EUA. Através da repressão, tentaram empurrar os sem-abrigo e os visivelmente pobres para fora do centro da cidade. E não sabemos exactamente onde estão, porque foram obrigados a mudar para cidades mais pequenas, outros foram presos, outros morreram... Em São Francisco continuam a ser visíveis, porque é uma cidade mais...

LF ... com um clima melhor?

PB Mas não é só isso! Nova Iorque, com um clima terrível, tinha uma população sem-abrigo maior que a de São Francisco. Viviam nas estações de comboio, em lugares públicos mas dentro destes. Mas estas pessoas já não estão tão visíveis.

LF Estás a referir-te às políticas de tolerância zero?

PB Sim, exactamente. Que estão mais fortes nestes últimos dez anos do que quando escrevi o In Search of Respect e quando pensei no trabalho que estou a fazer agora, sobre os sem-abrigo nos bairros de heroína e crack, que agora não podem ter grandes acampamentos como tinham quando fiz aquela apresentação na Faculdade de Psicologia do Porto. Vivem agora em grupos muito mais pequenos. E a maioria das pessoas da rua vive em sítios de forma mais temporária. Movem-se mais frequentemente ou vivem em veículos abandonados que estão na rua e que são retirados quando são limpas as ruas.

LF A forma como abordas estas questões sugere uma implicação política da análise etnográfica, digamos, uma "etnografia política".

PB Quero entender o fenómeno, mas quero entendê-lo para comunicá-lo de forma visível para as pessoas e de forma a que seja reconhecido como o que é. Então, neste sentido, quero ser um intelectual público. Mas não quero perder uma perspectiva analítica do fenómeno. Realmente quero entendê-lo...

LF Eu perguntava-te isto porque às vezes parece-me que os trabalhos no campo da etnografia e da antropologia em geral são um pouco despolitizados, nem sempre se ligam à questão mais geral de saber o que está a acontecer à sociedade.

PB Pois, esse é o problema de todos nós, os académicos, com o seu habitus escolástico. Mas ao mesmo tempo, sendo eu um académico perdido que adora ler, escrever e inventar termos que me facilitem a análise... Por exemplo, agora estou 
com uma redefinição da categoria de classe lumpen, pois eu penso que o momento histórico em que estamos realça a importância desta categoria da população.

\section{LF Queres reabilitar a concepção?}

PB Marx, que inventou a palavra, não a utilizou de maneira muito precisa. Utilizou-a mais como um insulto para os seus inimigos - como o Bonaparte a quem ele chamou lumpen, príncipe lumpen e coisas assim. Mas, afinal, esses sectores da população que ele identificou como lumpen são muito interessantes. Não é só uma classe social - é um adjectivo, um qualificativo. Porque pode ser de qualquer classe desde que empurrada para fora de qualquer relação produtiva com o que se está a passar com a economia e com a organização social do Estado. Então, estou a agregar não só o conceito de modo de produção de Marx, mas também os conceitos de Foucault de subjectividade, de governamentabilidade e de biopoder, para entender o fenómeno do lumpen. Porque o que vejo é que com todo o aparelho de Estado, que para todos nós tem sido produtivo (o sistema de saúde, o sistema de educação, todas essas coisas que nos fazem viver mais tempo)...

LF ... as instituições da sociedade disciplinar?

PB Sim, que nos fazem viver mais tempo, com mais saúde. Talvez não mais felizes, mas pelo menos mais saudáveis fisicamente. Assim, eu creio que estas mesmas instituições, para um sector crescente da população, estão a ser abusivas. Em vez de ter um efeito disciplinar produtivo, contentor, isto está a ter um efeito abusivo, que resulta em subjectividades e em formas de viver a sua vida que são mais violentas, duras e piores do que eram quando não existiam estas instâncias.

\section{LF Mas falas apenas pela tua experiência nos Estados Unidos?}

PB Eu creio que é diferente na Europa. É certo que vocês têm uma história, desde logo de movimentos, de classes e organização da sociedade com sectores de classe, que fez com que houvesse uma maior organização do Estado enquanto distribuidor de serviços e de rendimentos. Mas esta está, de certo modo, a diminuir...

LF Então o que terá acontecido em Paris, em 2005, com os incêndios?

PB Claro que é diferente! O peso do Estado social-democrata foi sendo mais forte na Europa do que nos Estados Unidos e assim vocês, europeus, não têm tanta gente na rua com a mesma facilidade que nós. Intervêm mais nas famílias e mais nos níveis de stresse do que nós. 
LF Parece-me que houve um ponto em que a etnografia e o trabalho técnico se encontraram na rua: foi a propósito da redução de riscos e minimização de danos, nomeadamente no que diz respeito ao trabalho na área das drogas. Pela primeira vez, a investigação sobre os ambientes, os actores e os produtos psicoactivos que circulam na rua, a etnografia e a intervenção técnica no campo das drogas estão juntas e no mesmo cenário - a rua, as partes "más" da rua. Falo, portanto, da redução de danos como mecanismo de suporte a populações mais frágeis e mais marginalizadas. Concordas que é assim? E como é nos Estados Unidos?

PB Estou a analisar esse fenómeno do movimento de "redução de riscos e de minimização de danos" e uma coisa que verifico é que um tema que tratamos ao trabalhar em saúde pública é que esquecemos muito que nos EUA, apesar de alguma retórica da parte dos académicos, a redução de danos não existe, não é uma política de Estado. É ilegal utilizar dinheiro do Estado federal para a troca de seringas e, pior, basta utilizar a expressão "redução de danos" numa publicação nos EUA para não conseguir qualquer tipo de financiamento do Estado. É incrível... não podemos utilizar esta expressão, mas agora a maioria das publicações está a utilizar a expressão "redução de riscos". Se utilizar a expressão "redução de danos" numa proposta de financiamento, não se consegue obtê-lo. É como a palavra "comunista” nos anos 50. É uma irracionalidade! Já o termo "risco" tem um sentido puritano - de controlo dos riscos, de tomada de responsabilidade individual pelos riscos.

LF Estás a dizer que está mais relacionado com a prevenção...

PB Então, em saúde pública, poderia existir, sim, a concepção de "redução de riscos". Mas utilizar a expressão "redução de danos" é como incentivar ao consumo, é como dizer aos jovens que consumir drogas é uma coisa boa. É esta a mentalidade. A maioria dos políticos, em público, não tocaria neste tema nem por nada. E agora, existe mais financiamento para coisas como a abstinência total, trocar as drogas pela religião, nem sequer gostam que falemos de preservativos... Esquecemos que os serviços de drogas que estão acessíveis à população americana não são os da saúde pública, são os da prisão. A maioria das pessoas que deixa de consumir está na cadeia, e sem nada, sem metadona, vomitando no chão da prisão... este é o método do tratamento público de drogas. Não temos tratamentos de drogas para a maioria das pessoas.

LF Mas nesse aspecto há uma diferença muito grande em relação ao que se passa na Europa. Porque na Europa o movimento da redução de riscos é forte neste momento. 
PB Sim, é um sentido público de todos, até os políticos de direita quase que já falam de redução de danos. Não querem ser vistos como gente que não é moderna, que é arcaica.

LF Antes de te interessares pelo Harlem, pela sua zona porto-riquenha do El Barrio e pelas drogas que aí circulavam nas ruas, interessaste-te pelas plantações de bananas na Costa Rica... E depois andaste pela Nicarágua, por El Salvador... O que contas disto?

PB O meu primeiro trabalho foi na América Central. O primeiríssimo foi em Belize, onde estava a fazer a minha tese de mestrado, em 1978. E depois quando estava a fazer a tese de doutoramento rebentou a revolução nicaraguense, em 1979. Então eu pensei: isto será muito mais interessante para analisar! Eu andava numa aldeia de Mopan Maya, em Belize, na fronteira com a Guatemala. E era interessante porque se tinha construído uma estrada na zona e havia alterações muito rápidas na organização do trabalho e do mercado local. E eu percebia que a situação ia ser muito má, essencialmente para os camponeses da zona indígena. E quando rebentou a revolução nicaraguense trabalhei na reforma agrária para fazer a minha tese de doutoramento aí. Mas, como eu era antropólogo e europeu, eles disseram que eu ia adorar os índios. Viam-me como francês porque eu tinha passaporte francês e porque tinha vergonha de ser gringo (nasci em França e vivi na Suíça, mas também vivi em Nova Iorque, pelo que tenho dupla nacionalidade, ainda que culturalmente me diga americano). As perspectivas críticas que tenho resultam, talvez, da influência antiamericana do meu pai.

\section{LF A tua mãe é de Nova Iorque, não é?}

PB É de Filadélfia, mas vive em Nova Iorque. Eu critico a política do meu país, mas sinto-me em casa nos EUA, este é o meu país. Voltando à Nicarágua, mandaram-me para a zona misquita, indígena dos ameríndios misquitas, para trabalhar com a reforma agrária, na costa atlântica, para escrever um diagnóstico do que deveria ser a reforma agrária na zona indígena.

\section{LF Trabalhavas para o Ministério?}

PB Sim. Queria fazer antropologia aplicada. Nesta época, trabalhava em estudos camponeses e indígenas, essa era a minha formação antropológica, e um pouco sobre o desenvolvimento económico, para tratar da questão da globalização e da introdução do mercado nas sociedades de subsistência (isto em 1979). Foi então que vi a mobilização indígena pelos direitos culturais. E foi trágico, porque o governo sandinista, que tinha boas ideias acerca das questões 
dos camponeses latinos, não lograva entender a questão indígena como uma questão nacionalista, mas via-a como um insulto à força do Estado central. E instalou-se uma guerrilha indígena pela defesa dos seus direitos, porque os indígenas estavam animados com a revolução, com toda a retórica dos direitos, da mobilização dos pobres pelos seus direitos. E todos se mobilizaram e reclamavam uma autonomia regional e o Estado não o entendia. Os EUA meteram-se, com a CIA também, e começaram a financiar a guerrilha dos misquitos. Foi um momento triste porque a mobilização dos indígenas era legítima. Porque havia um racismo bárbaro contra os indígenas, nos países latino-americanos. Então nós, a equipa da reforma agrária, escrevemos um relatório dizendo que teriam de dar a autonomia regional aos indígenas e reconhecer as suas reivindicações quanto aos seus idiomas, a sua cultura e o controlo dos recursos naturais da sua zona. O governo central não aceitou e retiraram-me do país. A guerrilha aumentou e foi muito violento. Em 1984, três anos mais tarde, os sandinistas fizeram uma mudança radical na sua política, cederam a autonomia regional aos indígenas e devolveram-me o direito de voltar, convidando-me a participar neste projecto de autonomia... Voltei e ainda fiz um pequeno relatório, mas nesse tempo já estava a terminar o meu doutoramento sobre uma plantação de bananas, na zona atlântica da Costa Rica, na fronteira entre o Panamá e a Costa Rica. Saiu como um livro, escrito em espanhol, Banano, Etnia e Lucha Social en Centro America, publicado na Costa Rica. ${ }^{3}$ Este foi o meu primeiro livro.

Depois saiu um estudo sobre a guerrilha salvadorenha, ${ }^{4}$ que estava mais forte nesse tempo. Pensava, inclusivamente, fazer um trabalho com os refugiados nas zonas de controlo da guerrilha...

\section{LF E neste tempo estavas a trabalhar em alguma universidade americana?}

PB Sim, eu era estudante de pós-graduação em Stanford e estava a terminar, ou seja, à procura de um tema para fazer o meu trabalho etnográfico. Então, antes de fazer o estudo da plantação bananeira e depois de ter saído da Nicarágua (porque eu pensava que o meu doutoramento ia ser sobre os misquitos e a participação dos indígenas na revolução sandinista, mas depois houve o desastre), saí para El Salvador, para saber se era possível trabalhar nas zonas das guerrilhas salvadorenhas. Então caí, por azar, numa invasão do Estado e passei 14 dias a viver com a população civil, debaixo de bombardeamentos. O exército rodeava uma zona, neste caso de cerca de $20 \mathrm{Km}^{2}$, e matavam todos os seres humanos que viviam nessas zonas e queimavam as casas

3 Em inglês: Philippe Bourgois, 1989, Ethnicity at Work: Divided Labour on a Central American Banana Plantation. Baltimore e Londres, Johns Hopkins University Press.

4 Philippe Bourgois, 2001, "The power of violence in war and peace: post-Cold War lessons from El Salvador”, Ethnography, 2 (1): 5-34. 
e as plantações. É a técnica que aprenderam no Vietname, que os EUA lhes ensinaram. Mas não utilizaram napalm em El Salvador. Utilizaram fósforo, que queima... foi morta muita gente, utilizando-se o dragon-fly. Matou-se muita gente, ainda que não com o mesmo nível de bombardeamento que se utilizava no Vietname, pois esse era muito mais alto e mais "tecnificado".

Então não pude seguir o meu projecto como projecto de doutoramento. Assim segui um projecto sobre direitos humanos, já que tinha fotos daquela matança, da qual escapei. E saí como refugiado para as Honduras. Éramos 2000 pessoas. Creio que morreram 250 pessoas. Vinham com helicópteros, os mesmos que se utilizam nos EUA para perseguir os gangues e para organizar o trânsito. Mas não são eficientes... As pessoas conseguem esconder-se nas montanhas. Corríamos de dia e escondíamo-nos de noite. Depois saímos como refugiados para as Honduras. Então trabalhei em direitos humanos por uns seis meses e voltei finalmente para a Costa Rica e para o Panamá para fazer a minha tese.

LF Depois disto, parece-me que a tua experiência no El Barrio foi suave... Para além da excelência do teu trabalho no El Barrio, há outro aspecto que te tornou famoso: mistificou-se a ideia de que estiveste num terreno considerado muito perigoso, fazendo etnografia num sítio arriscado.

PB Sim. É certo que havia muita violência, especialmente no período de início do crack, em meados dos anos 80 e princípio dos 90, mas a verdade é que a maioria da população destes bairros vive aí sem problemas, sem ser morta. Contudo, era perigoso passar as noites nas casas de crack. Mas também me sentia protegido pelos companheiros com quem tinha travado amizades. Eles queriam que documentasse as suas vidas. Mas é claro que eu também, às vezes, sofria violência de inimigos, assaltantes e rivais. Havia também o medo da polícia. Tínhamos medo de que a polícia nos mandasse a todos para a prisão e de aí sermos violados. Nas prisões há sempre alguém que não se sabe defender... E de facto, aí não saberia como defender-me. Ainda assim, eles disseram-me que, se fôssemos presos, eles me defenderiam de ser violado - não queriam que eu fosse violado -, mas eu tinha um pouco de medo.

\section{LF Antes de ires para lá, o Harlem era-te longínquo?}

PB Eu cresci no 96 da rua Madison, vendo o fenómeno do gueto, lendo as autobiografias de Malcolm X, Piri Thomas, Claude Brown, clássicos escritos sobre Harlem, enquanto era adolescente. E dava conta de que um enorme fenómeno de injustiça estava a acontecer a uns sete quarteirões de minha casa. Então eu queria perceber isso, pelos métodos da antropologia e pela sistematização dos estudos urbanos e de etnicidade, queria entender este fenómeno. Era também o período de Reagan, em que cortaram os subsídios da universidade, 
pelo que me encontrei sem dinheiro. Fui para Harlem, porque aí era mais barato conseguir um apartamento. E então escrevi o meu doutoramento sobre a plantação bananeira vivendo em Harlem. Mudei-me para lá em 1984, quando terminava o doutoramento.

\section{LF Então o In Search of Respect não é a tua tese de doutoramento...}

PB Não, o In Search of Respect era o meu segundo livro. O meu segundo terreno de longo prazo... o projecto da Nicarágua era para ser a médio/longo prazo, mas não o pude seguir. E o In Search of Respect foi mais longo do que a minha tese de doutoramento porque vivi um período de cerca de dois anos e meio na rua, no East Harlem, num período entre 1985 e 1991, enquanto estava à procura de trabalho. Tinha um pós-doutoramento em Paris, na École Normal Supérieure, e depois, por uns nove meses, consegui o meu lugar na San Francisco State University, e finalmente consegui três anos de bolsas que me permitiram residir no bairro a tempo completo.

LF E depois contas no livro o resto da história, que é fantástica. O In Search of Respect é para nós, que trabalhamos na área, um marco na história da etnografia urbana. Agora pensas voltar ao mesmo local, com os filhos dos teus informantes dessa época, não é verdade?

PB Essa é uma das minhas ideias. Terminei esta semana o meu livro sobre os sem-abrigo. Estou agora, como dizemos em antropologia, num momento liminar, terminei este trabalho e agora tenho de pensar e definir o que fazer. Fui de férias a Nova Iorque e visitei em primeiro lugar o Primo, o personagem principal do In Search of Respect, com quem mantive amizade ao longo destes anos. E pensei que deveria, com disciplina, passar tempo com ele e com os seus filhos, e com os filhos dos outros do círculo de Primo, para ver como têm vivido de 1991 até hoje, para ver os efeitos da agudização do modelo neoliberal de que falámos e, sobretudo, os efeitos da guerra contra a droga, porque, para dizer a verdade, a guerra contra a droga tinha sido declarada por Nixon, mas não na escala em que Bush-pai a conduziu e a agudizou. Foi também muito agudizada pelos chefes do governo municipal de Nova Iorque, que eram os principais porta-vozes da tolerância zero de Giuliani (quando eu terminei o In Search of Respect ele não estava ainda no governo da cidade).

LF É curioso, porque aqui na Europa refere-se Giuliani como alguém que criou uma forma de controlar a extensão da delinquência urbana e a Nova Iorque dos anos 90 como um modelo. Mas eu li no posfácio da tua versão francesa do In Search of Respect que o vias como tendo tido um impacte negativo nas zonas mais marginais de Nova Iorque. 


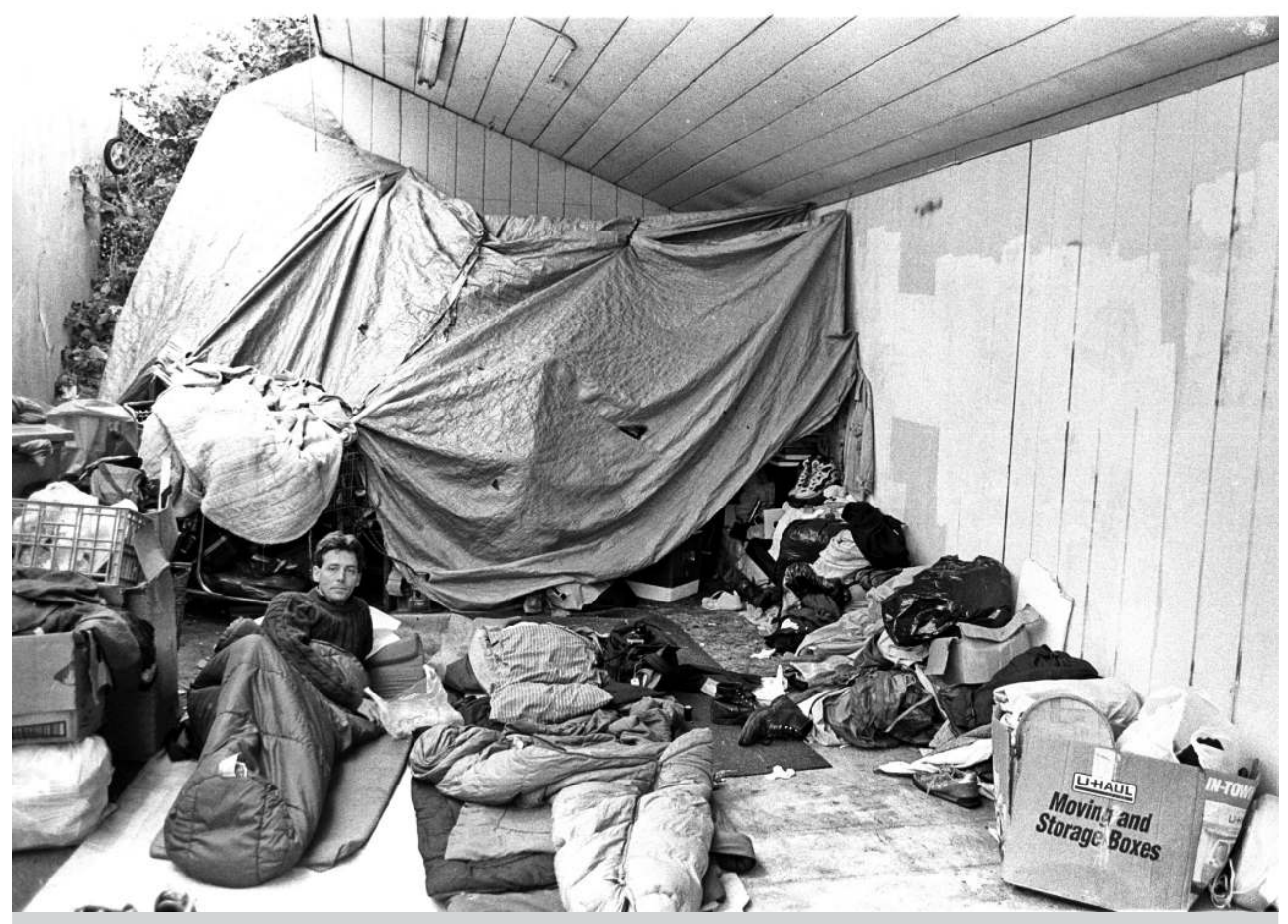

Acordar num acampamento de sem-abrigo. (Fotografia de Jeff Schonberg)

PB O que é interessante com todo este debate do que são os efeitos da política de tolerância zero é que, essencialmente, as estatísticas - e nós bem sabemos como há sempre debates intermináveis sobre o que significam as estatísticas... - do crime, violência e criminalização dizem que o efeito do encarceramento só diminuiu... não sei exactamente os valores, mas foi mais ou menos $12 \%$. O efeito dum aumento tão caro e tão imenso da guerra contra a droga só representa $12 \%$ de diminuição. E sabemos isso porque certas cidades que não seguiram o modelo do combate contra a droga e das políticas de tolerância zero (porque nos EUA existe muita autonomia regional) também tiveram as mesmas diminuições da violência e do crime. Então é claro que estavam a responder a outros efeitos, de alterações mais estruturais da economia, que estavam a acontecer. Mas não as percebemos claramente, pelo que nós antropólogos e sociólogos temos de nos saber criticar, admitindo que ainda não sustentámos esta questão com suficiente clareza para realmente entendermos o porquê e o quando destas variações do crime.

Agora há um aumento muito grande da violência e do homicídio nos EUA, e não se explica com nada. Com o crack tínhamos uma explicação, e não era exactamente o novo mercado de crack, mas as formas mais violentas de controlo do território, as lutas entre gangues por este novo mercado. A máfia tradicional 
tinha perdido o seu controlo histórico, porque dominava o mercado da heroína mas o crack era comercializado por elementos mais pequenos, que são sempre mais violentos do que a máfia tradicional, que é mais organizada. Mas agora não temos explicação. Não há nenhuma nova droga, mas há um aumento muito acentuado nas matanças entre jovens, especialmente em bairros afro-americanos e latinos. Filadélfia, para onde me estou a mudar para trabalhar na Universidade da Pensilvânia, tem uma taxa de homicídios incrível entre a população afro-americana jovem.

LF Filadélfia era a cidade de Goffman, certo?

PB Sim, Goffman era de Filadélfia e esta tinha uma tradição interdisciplinar de estudos urbanos muito boa. Há uns historiadores muito bons sobre zonas urbanas e pobreza.

LF A primeira vez que vi um artigo teu foi nas Actes de la recherche, "Une nuit dans une shooting gallery", 5 em 1992, estava eu a começar o meu trabalho de rua num bairro problemático do Porto. Tiveste contacto com o círculo de Bourdieu nessa altura?

PB Sim, sobretudo através de Loïc Wacquant. Foi ele que me apresentou a Bourdieu, e foi Bourdieu, de facto, que traduziu o In Search of Respect para francês. Participei em vários eventos que o círculo de Bourdieu organizou. Foi uma honra tê-lo conhecido. Foi muito simpático para comigo, e inclusive veio visitar o meu terreno em São Francisco, um acampamento dos sem-abrigo.

\section{LF Assim como também levaste Robert Merton ao El Barrio...}

PB Sim, Robert Merton não saiu do carro. Parou para ver as casas de crack. Ainda o convidei para entrar, mas ele tinha 82 anos... Era muito simpático e tranquilo. Ele leu e fez comentários ao manuscrito do In Search of Respect. Era muito generoso com o seu tempo. Gostava de ler os manuscritos etnográficos dos jovens que se iniciavam.

LF Fizeste o mesmo terreno que Oscar Lewis, não foi?

PB Oscar Lewis trabalhou nos tugúrios porto-riquenhos e também no El Barrio e no South Bronx. 
LF Mas o teu trabalho não tem a ver com o dele...

PB Bom, o meu trabalho é uma crítica teórica à conceptualização da cultura da pobreza. O que eu vejo é que aquilo a que se chamava teoria da cultura da pobreza não era teoria mas, sim, uma descrição etnográfica muito rica. Oscar Lewis realmente fez um trabalho de longo prazo muito rico e a sua relação com as pessoas que estudou era profunda, com muita empatia e simpatia. Mas não tem análise. Ele escreveu na introdução de La Vida o que se diz ser a teoria da cultura da pobreza. Mas realmente não é nada sistemática, é uma mistura de cultura com personalidade, de questões estruturais e culturais. Não tem sentido, de certo modo. Eu respeito Oscar Lewis pelo seu estudo etnográfico e por ter tornado a pobreza um tema respeitável e legítimo para a antropologia e para a etnografia - antes dele não havia quase nada...

\section{LF Só a Escola de Chicago...}

PB Sim, com os sociólogos. Mas era um pouco diferente, estudavam mais os migrantes na cidade e coisas assim. O problema com Oscar Lewis (eu li um pouco da sua biografia) é que ele não gostava de teoria. Gostava de fazer etnografia. Ele disse em algumas cartas: "não creio que a cultura da pobreza exista mas as pessoas gostam deste termo"...

LF No Porto disseste mesmo que ele utilizava o conceito de cultura da pobreza para calar os críticos.

PB Sim, as pessoas criticavam-no por não ser teórico. Mas ele era alguém que tinha muita ambição, queria ser conhecido no mundo...

\section{LF E conseguiu!}

PB Sim, conseguiu. Praticamente só Margaret Mead, nos EUA, conseguiu ter mais êxito entre os antropólogos. É um dos poucos intelectuais públicos que temos, pois em geral não os temos.

LF Com o termo "intelectual público" queres referir-te a alguém que se envolve em temas críticos para a sociedade?

PB Exactamente, que trata de abordar temas que o público em geral quer e necessita de conhecer. Margaret Mead é conhecida porque estudou questões relacionadas com a sexualidade e com os direitos das crianças.

LF E agora temos Philippe Bourgois, não é? 
PB Não, não! [Risos] Temos de ser humildes e realistas... As pessoas nos EUA não lêem, agora.

LF Aqui na Europa, pelo menos no campo das drogas, nós lemos-te. Para os que estão mais próximos do terreno, para os que seguem uma abordagem mais sociocultural, és uma referência.

PB Obrigado por dizeres isso. Espero que haja uma boa discussão destes temas na Europa, onde o campo da antropologia urbana e dos estudos sobre pobreza e droga estão a desenvolver-se muito rapidamente. Também tem uma história muito própria e que eu aprecio particularmente (conheço sobretudo a antropologia urbana francesa). Mas, no que diz respeito à droga, tivemos oportunidade de estudar estes temas antes, porque tínhamos os fenómenos mais visíveis. O junkie tinha uma visibilidade maior nos EUA. Já nos anos 50 e 60 tínhamos este fenómeno.

LF Uma última questão sobre a etnografia, porque estamos a falar para a revista Etnográfica. A etnografia é um estilo de pesquisa e, dizem os literatos, o estilo é um desvio à norma. O estilo é algo muito pessoal. O que é a etnografia para ti, a partir da tua experiência?

PB Bom, às vezes creio que a etnografia é a minha terapia pessoal. É a minha forma de ter um pouco de contemplação e de controlo no mundo, porque eu vejo que converto a minha vida pessoal - e é assim que dou sentido e animação a tudo o que faço - numa relação etnográfica. Adoro estar com gente, estar no social e com o público, fascinam-me as pessoas. Não consigo parar de analisá-las e ser curioso em relação à sua vida... Por vezes, isto tornou-se problemático. Por exemplo, no meu primeiro casamento, a minha esposa já não aguentava que eu estivesse tão fascinado com ela e com a sua família (ela era centro-americana e a sua família era originária do campo). De certo modo, a minha relação com a etnografia é quase patológica. Inclusivamente, fiz um estudo sobre o meu pai recentemente. E foi formidável para a nossa relação, porque ele é um sobrevivente de Auschwitz, não dos campos de morte, mas sim dos campos de trabalho (não era judeu, portanto não o iam matar), era um trabalhador forçado.

LF Fizeste, então, um trabalho biográfico?

PB Sim. Bem, fiz uma série de entrevistas com ele. Foi bom, porque converti a minha relação com ele numa relação etnográfica muito intensa. Durante quatro ou cinco anos entrevistava-o amiúde e até fui a Auschwitz com ele. 
LF Que fizeste com esse material?

PB Fiz um pequeno artigo, que vai ser agora traduzido em francês para as Actes de la recherche. Foi publicado no Anthropological Quarterly. ${ }^{6}$

LF Olhando para os terrenos de estudo que escolheste (Harlem, depois um acampamento de toxicómanos em São Francisco), podemos dizer que se trata de uma etnografia radical?

PB Sim, mas ao mesmo tempo são sítios fáceis. São todos perto da minha casa e as pessoas sempre me trataram de modo muito amável. Todas as minhas experiências na rua (com excepção daquela em El Salvador, com a guerra) têm sido quase sempre um grande prazer, muito mais fáceis do que as minhas experiências com os meus colegas académicos, diria! [Risos] ${ }^{7}$

6 Philippe Bourgois, 2005, "Missing the Holocaust: my father's account of Auschwitz from August 1943 to June 1944”, Anthropological Quarterly, 78 (1): 89-123.

7 A pesquisa de Philippe Bourgois foi financiada principalmente pela bolsa R01DA010164 dos National Institutes of Health (NIH), beneficiando actualmente do financiamento adicional das bolsas MH078743, DA017389, DA021627 e CHRP126774. 